\title{
Exploring Valuable Lipids in Diatoms
}

\author{
Zhiqian $\mathrm{Yi}^{1+}$, Maonian $\mathrm{Xu}^{2+}$, Xiaxia $\mathrm{Di}^{2+}$, Sigurdur Brynjolfsson ${ }^{1}$ and Weiqi $\mathrm{Fu}^{1,3 *}$ \\ ${ }^{1}$ Center for Systems Biology and Faculty of Industrial Engineering, Mechanical Engineering and Computer Science, School of \\ Engineering and Natural Sciences, University of Iceland, Reykjavik, Iceland, ${ }^{2}$ Faculty of Pharmaceutical Sciences, University \\ of Iceland, Reykjavik, Iceland, ${ }^{3}$ Division of Science and Math, Center for Genomics and Systems Biology, New York University \\ Abu Dhabi Institute, New York University Abu Dhabi, Abu Dhabi, UAE
}

\section{OPEN ACCESS}

Edited by:

Roland Wohlgemuth, SIGMA-ALDRICH, Member of MERCK

Group, Switzerland

Reviewed by:

Adrianna lanora,

Stazione Zoologica Anton Dohrn, Italy

Grigorios Krey,

Hellenic Agricultural

Organization-DEMETER (former NAGREF), Greece

*Correspondence:

Weiqi Fu

weiqi@hi.is,

wf21@nyu.edu

tThese authors have contributed equally to this work.

Specialty section:

This article was submitted to

Marine Biotechnology,

a section of the journal

Frontiers in Marine Science

Received: 10 November 2016 Accepted: 13 January 2017

Published: 30 January 2017

Citation:

Yi Z, XU M, Di X, Brynjolfsson S and Fu W (2017) Exploring Valuable Lipids in Diatoms. Front. Mar. Sci. 4:17. doi: 10.3389/fmars.2017.00017
Diatoms are one major group of algae in oceans that accounts almost half of marine primary food production and have also been identified as a promising candidate for biofuel production for their high level accumulation of lipids. They have gained increasingly attention for their potential applications in pharmaceuticals, cosmetics, nutrient supplements, and biofuels. This review aims to summarize the recent advances in diatom lipid study. Chemical structures and bioactivities of different lipid classes are discussed with a focus on valuable lipids such as fatty acids, polar lipids, steroids, and oxylipins from various diatoms species. Further, current extraction and fractionation approaches are compared and recent analytical techniques and methods are also reviewed with an emphasis on lipid class composition and fatty acid profiling. Biosynthetic pathways and key catalyzing enzymes are illustrated for a better understanding of fatty acid metabolism. Past engineering attempts toward generating appropriate diatom strains for lipid production are discussed with examples using mutagenesis, environmental stimulants, and genetic modification methods. Some possible future directions and applications of diatom-derived lipids are also proposed.

Keywords: diatoms, fatty acids, oxylipin, lipid production, value-added products

\section{INTRODUCTION}

Diatoms, representing one major group of photosynthetic algae, are unicellular eukaryotes that live within cell walls made of silica $\left(\mathrm{SiO}_{2}\right)$ (d'ippolito et al., 2015). They play an essential role in global carbon and silicon recycling in the ocean and their photosynthetic activity accounts for almost half of marine primary production. Over 8000 species are recorded worldwide in fresh water and oceans and it was estimated that there are 20,000-200,000 extant diatom species in the world (Mann and Droop, 1996; Appeltans et al., 2012; Guiry, 2012).

Diatoms have attracted increasing attention for their potentials in producing a variety of bioactive compounds and fine chemicals for industrial applications (Vinayak et al., 2015). For example, diatoms are rich in pigments such as carotenoids that have been widely applied in food supplements and feeds, pharmaceutical ingredients, and cosmetics (Vilchez et al., 2011; Fu et al., 2015). The major carbon storage compound in diatoms is lipids, among which triacylglycerides (TAGs) and fatty acids usually make up 15-25\% of dry biomass (Mangas-Sanchez and Adlercreutz, 2015).

Diatom feedstock is a promising candidate for developing a variety of value-added bio-products toward a sustainable bio-economy. However, diatoms are clearly underexploited from an engineering perspective. In this review, attempts have been made to emphasize valuable lipid products in diatoms. Chemical structures of lipids and their bioactivities as well as analytical 
methods and biosynthetic pathways are described for a better understanding of lipid products. Various existing and emerging techniques on generating appropriate diatom strains are also discussed. We envision it is feasible to produce valuable lipid products from diatoms with the rapid development of cell factories in the near future.

\section{LIPIDS AND FATTY ACIDS IN DIATOMS}

Diatoms are a rich source of natural products (or bioactive compounds) that may be developed as candidate marine drugs. A large variety of lipids can be generated in diatoms, in addition to other types of bioactive compounds such as pigments (Michalak and Chojnacka, 2015), halogen-containing compounds (Wichard and Pohnert, 2006), toxic domoic acid and isomers (Bates and Trainer, 2006), attractants and deterrents (Frenkel et al., 2014), and long chain polyamines with biomineralizing functions (Kröger et al., 1999). Lipids are the major constituents of diatom cells and the average lipid content in diatoms could achieve to $25 \%$ of dry weight (Levitan et al., 2014), although the production of lipids in diatoms can vary on culture conditions. In this section, we will give an overview on valuable lipids from diatoms, referring to the multiplicity of structural groups, and biological roles.

\section{Fatty Acids}

Most fatty acids in diatoms (as shown in Table 1) vary from C14:0 to C22:6. The most common fatty acids are myristic acid (14:0), palmitic acid (C16:0), palmitoleic acid (C16:1n-7), DHA, and EPA (Opute, 1974; Jiang et al., 2016). The number of double bonds in fatty acid chains is usually two or three, and rarely more than six. Many known microalgal species have similar fatty acid profile, but fatty acid content in each species varies and it mainly depends on the strains and culture conditions (Opute, 1974; Stonik and Stonik, 2015; Jiang et al., 2016). EPA was one of the most characterized fatty acids in diatom lipids (Stonik and Stonik, 2015), while small portion of rare C24-C28 polyunsaturated fatty acids (PUFAs) were also found in diatoms and other microalgae (Mansour et al., 2005).

EPA and DHA are the most valuable FAs found in many species of diatoms with relatively high levels (Dunstan et al., 1993). Some fatty acids in diatoms show intriguing biological activities, particularly the unsaturated fatty acids. For instance, $16: 3 n-4$ and $16: 1 n-7$, which are usually minor components of fatty acid fractions, are highly active against Gram-positive bacteria (Desbois et al., 2008). Omega-3 fatty acids such as EPA and DHA have been found to have effects in alleviating a number of health conditions (e.g., arteriosclerosis, hypertension, inflammation, microbial, viral, and tumor activity). EPA and

TABLE 1 | Valuable lipids in diatoms.

\begin{tabular}{|c|c|c|c|c|}
\hline Lipids Class & Valuable compositions & Representation & Bioactivities & Diatom sources \\
\hline & HTA & $16: 3(n-3)$ & Anti-bacterial & \\
\hline & Palmitoleic acid & $16: 1(n-7)$ & Anti-bacterial & All the diatoms produce fatty acids but the content in \\
\hline \multirow[t]{4}{*}{ Fatty acids ${ }^{\mathrm{a}}$} & Stearic acid & 18:0 & Antimicrobial & each species varies. \\
\hline & Remenic acid & $18: 2(n-7)$ & Antimicrobial & \\
\hline & EPA & $20: 5(n-3)$ & $\begin{array}{l}\text { Anticancer, antimalarial, anti-bacterial, } \\
\text { anti-inflammatory }\end{array}$ & $\begin{array}{l}\text { Skeletonema menzelii and P. tricornutum have the } \\
\text { potential for commercial production of EPA and DHA. }\end{array}$ \\
\hline & $\mathrm{DHA}$ & $22: 6(n-3)$ & & \\
\hline$T_{A} G^{b}$ & TAG & & Biofuels & $\begin{array}{l}\text { TAGs in Thalassiosira weissflogii and C. cryptica may } \\
\text { account for } 82 \% \text { and } 88 \% \text { of total glycerolipids, } \\
\text { respectively }\end{array}$ \\
\hline
\end{tabular}

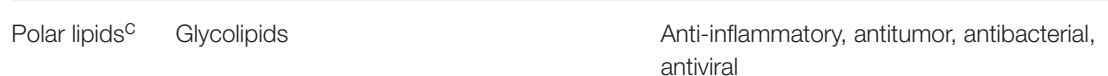
antiviral

Glycolipids were characterized by mass spectrometry in diatom species, such as T. pseudonana and Stephanodiscus sp.

Phospholipids

Valuable ingredient in functional foods, Phospholipids were identified in diatom species such as cosmetic, pharmaceutical industries P. tricornutum and Cylindrotheca fusiformis

\begin{tabular}{|c|c|c|c|}
\hline Steroids $^{d}$ & 24-methylenecholesterol & $\begin{array}{l}\text { Anti-inflammatory, antitrypanosomal, } \\
\text { anti-mycobacterial }\end{array}$ & $\begin{array}{l}\text { The sterol 24-methylenecholesterol accounts for } 90 \% \text { of } \\
\text { total sterols in Synedra acus. }\end{array}$ \\
\hline Oxylipins ${ }^{e}$ & PUAs & Antimitotic, anti-inflammatory, antimicrobial & $\begin{array}{l}\text { Some diatoms are a rich source of PUAs, such as } \\
\text { Thallasiosira rotula, but some do not produce oxylipins, } \\
\text { such as Skeletonema pseudocostatum. }\end{array}$ \\
\hline
\end{tabular}

a (Kabara et al., 1972; Hallahan and Garland, 2005; Desbois et al., 2008; Lafourcade et al., 2011; Sapieha et al., 2011; Valenzuela et al., 2012; Hamilton et al., 2015; Jiang et al., 2016). ${ }^{b}$ (d'ippolito et al., 2015).

c(Yongmanitchai and Ward, 1992; Plouguerné et al., 2014; d'ippolito et al., 2015; da Costa et al., 2016).

d(Volkman et al., 1998; Viegelmann et al., 2014).

e'(Paul and Fenical, 1986; Nappez et al., 1996; Girona et al., 1997; Caldwell, 2009; Lauritano et al., 2016). 
DHA play important roles in protecting cardiovascular system (Sapieha et al., 2011), vision (Hallahan and Garland, 2005), and treating psychiatric disorders (Lafourcade et al., 2011).

The omega- 6 and omega- 3 fatty acids are important fatty acids in cell membranes (Nakamura and Nara, 2004). Although humans and other mammals can synthesize saturated fatty acids and some monounsaturated fatty acids from carbon groups in carbohydrates and proteins, they lack necessary enzymes to insert a cis double bond to the n- 6 or the n-3 position of fatty acid (Trumbo et al., 2002). Humans can synthesize EPA and DHA from a linolenic acid (18:3n-3) (ALA) through a series of desaturation (addition of a double bond) and elongation reactions (Nakamura and Nara, 2004). However, due to low conversion efficiency, it is recommended to obtain EPA and DHA from additional dietary sources. Long-chain omega-3 PUFAs in particular have anti-inflammatory properties and a variety of seafood is recommended for daily intake of omega-3 PUFAs (Nakamura and Nara, 2004; Jump et al., 2012).

\section{Triacylglycerols (TAGs)}

Diatoms are considered to be sources for sustainable production of biofuels as they accumulate a large amount of TAGs efficiently. However, TAGs in diatoms vary within the species and the genera (Thompson, 1996). Myristic acid (14:0) and palmitoleic acid (16:1) were found to be the main fatty acids reported in diatoms while a variety of other species have been found in TAGs in diatoms (Hildebrand et al., 2012). C16 fatty acids account for nearly $100 \%$ of the total fatty acids at the $s n-2$ position of TAGs in diatoms, which include monounsaturated fatty acid palmitoleic 16:1 at a major level and unsaturated fatty acids C16:2 and C16:3 at a minor level (Li et al., 2014). Various stressors that induce changes in metabolic activities may enhance TAG contents in diatoms and the details will be elucidated in the later section.

\section{Polar Lipids}

The polar lipids from diatoms mainly consist of monogalactosyldiacylglycerol (MGDG), digalactosyldiacylglycerol (DGDG), sulfoquinovosyldiacy lglycerol (SQDG), phosphatidylcholine (PC), phosphatidylinositol (PI), phosphatidylglycerol (PG), and other minor constituents, such as 1-deoxyceramide-1-sulfate and phosphatidylsulfocholine which exist as rare sulfoforms (Anderson et al., 1978; Figure 1). Glycolipids are important components that locate mostly in chloroplasts and have been demonstrated to display antiviral, antibacterial and antiinflammatory activities (Plouguerné et al., 2014). Phospholipid molecules that are the universal components in cell membranes may be utilized as an ingredient in functional foods, cosmetic and pharmaceutical industries for their roles as carriers of PUFAs.

\section{Steroids}

A number of studies have shown that $\Delta^{5}$-series with 24 methylencholestrol (Figure 1) was the most common sterol, while diatomsterol (24-methylcholesta-5,22E-dien-3 $\beta$-ol) also frequently present in more than a half of the known pennate diatoms (Rampen et al., 2010). Sterols with methylation at
C-23 are also produced in various species of diatoms in addition to dinoflagellates (Rampen et al., 2009a,b). The majority of diatoms that have been explored mainly contain $\mathrm{C}_{28}$ sterols, although $\mathrm{C}_{27}$ or $\mathrm{C}_{29}$ sterols are proven to be the major sterol constituent in some phylogenetic groups. Other minor sterols such as stanols or $\Delta 7$-sterols have also been found in a small number of species. Although there is still not sufficient information about chemical profiling of sterols in diatoms, sterols and their derivatives were found to have important bioactivities such as cytotoxic, anti-inflammatory, antitrypanosomal, and antimycobacterial properties (Viegelmann et al., 2014).

\section{Oxylipins}

Oxylipins that derived from the incorporation of oxygen into the carbon chains of PUFAs usually act as chemical mediators in many ecological and physiological processes in marine and freshwater diatoms (Wichard et al., 2005; Sieg et al., 2011). Around $30 \%$ of marine diatoms produce an array of oxylipin metabolites (Wichard et al., 2005; Sieg et al., 2011). Biosynthesis of oxylipins (Figure 1) is condition-dependent and immediately activated upon predation (D'ippolito et al., 2005; Cutignano et al., 2011; Nanjappa et al., 2014). Particularly, oxylipin production starts by the oxidation action of iron non-heme enzymes lipoxygenases (LOXs) on the precursor PUFAs and membrane phospholipids upon loss of cell integrity (Orefice et al., 2015). A LOX provides a specific and precise incorporation of a hydroperoxide group into the carbon chains and mediate the further transformations, resulting in generation of a group of important oxylipins (Wichard et al., 2005).

Polyunsaturated aldehydes (PUAs) that were extracted from blooming diatoms are the best-studied metabolites among the diatom-oxylipin family. Studies on bioactive aldehydes have showed that these compounds may inhibit the growth of different marine invertebrates such as diatom predators and induce different responses in marine ecosystem (Caldwell, 2009; Lauritano et al., 2016). This property may explain the dynamics behind some blooms and also explain why oxylipin profiles can be used as an additional taxonomic identification tool, providing a functional feature to species characterization and morphological traits. Study on structure-activity relationship of oxylipins has revealed that the double bond geometry $\mathrm{E} / \mathrm{Z}$ has no effects on inhibiting the development of embryos of sea urchin egg while the inhibition is primarily due to the chain length, the $\alpha, \beta, \gamma$, $\delta$-unsaturated aldehyde element, and the side chain polarity of PUAs (Adolph et al., 2003). Moreover, the biological importance of PUAs has been increasingly noted for their antimitotic and proapoptotic properties (Nappez et al., 1996), anti-inflammatory activity (Girona et al., 1997), anti-cancer activity (Sansone et al., 2014) and antimicrobial properties (Paul and Fenical, 1986).

Additionally, a series of volatile alicyclic olefins, which are possibly phytoplanktonic pheromones, were identified in some diatom species. Three rearrangement products of dienehydroperoxides from lipoxygenase metabolites, bacillariolides I-III, which are formed at the cyclization of epoxyalcohols, were 
A
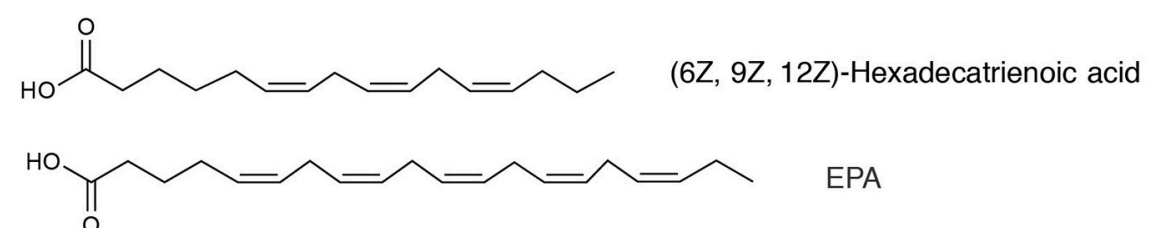

B

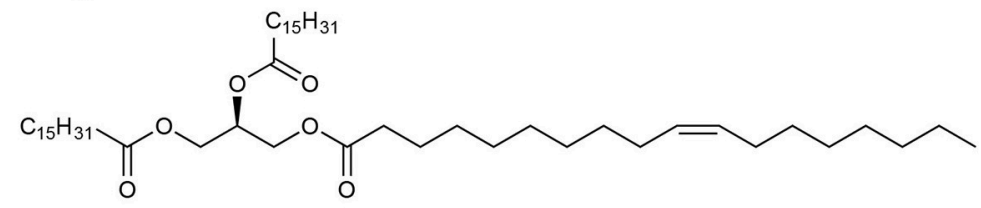

\section{1,2-dipalmitoyl-3-palmitoleoyl-sn-glycerol}

C<smiles>CC/C=C\C/C=C\C/C=C\C/C=C\C/C=C\CCCCCCCCCCC(=O)OCC(COP(=O)(O)CC[N+](C)(C)C)OC(=O)CCCCCCC</smiles><smiles>CC/C=C/C/C=C\C/C=C\C/C=C\C/C=C\CCCC(=O)OCC(COC(O)C1CC(C)C(O)C(O)C1O)OC(C)=O</smiles>

MGDG 20:5/16:0

D<smiles>C=C(CCC(C)C1CCC2C3CC=C4C[C@@H](O)CC[C@]4(C)C3CC[C@]12C)C(C)C</smiles>

24-Methylenecholesterol<smiles>CC(C)C(C)/C=C/C(C)C1CCC2C3CC=C4C[C@@H](O)CC[C@]4(C)C3CC[C@]12C</smiles>

24-Methylcholesta-5, 22-dien-3-ol

E
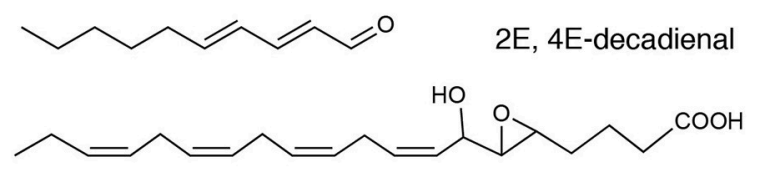

7-Hydroxy-5,6-epoxy-eicosa-8,11,14,17-tetraenoic acid

$\mathbf{F}$

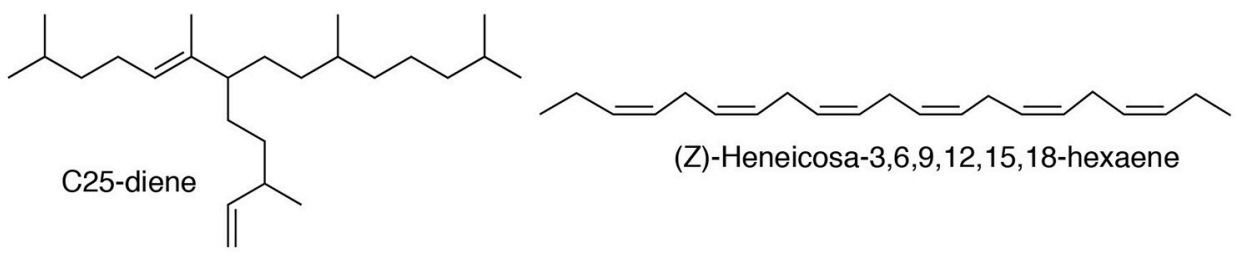

FIGURE 1 | Chemical structures of representative diatom-derived lipids. The compounds are classed into subgroups corresponding to structures. (A) Fatty acids; (B) Neutral lipids: TAG; (C) Polar lipids: PC and MGDG compounds; (D) Sterols; (E) Oxylipins; (F) Isoprenoids: C25 HBI.

extracted and isolated from marine diatom Nitzschia pungens (Wang and Shimizu, 1990; Zheng and Shimizu, 1997).

All together these studies provide additional information on the chemical diversity of oxylipins, which is particularly important in diatom taxonomy and physiology. Many of these compounds are well-characterized metabolites in diatoms. However, their biological functions are still not well understood and more efforts are needed to further study their impacts. 


\section{Isoprenoids}

Many classes of hydrocarbons including alkanes and alkenes are known in diatoms (Damsté et al., 2000). All-(Z)-heneicosa$3,6,9,12,15,18$-hexaene and n-21:6 hydrocarbon were found as major hydrocarbons in diatoms. A series of $\mathrm{C}_{25}$ highly branched isoprenoid (HBI) alkenes from the diatoms Haslea ostrearia, Rhizosolenia setigera, and Pleurosigma intermedium have been reported (Volkman et al., 1994; Grossi et al., 2004). Some representative HBI alkenes structures can be found in Figure 1. These hydrocarbons share the same parent carbon skeletons but exhibit differences in their degree of unsaturation (ranging from two to six double bonds). The main characteristic of this acyclic skeleton is an alkyl side chain at C-7 of the main chain. A large number of HBI isomers were produced in different diatoms that were cultivated under a series of growth conditions and determined by a combined spectroscopic and chromatographic analysis approach using NMR spectroscopy and chiral gas chromatography, respectively (Belt et al., 2001). Alkenes from the Haslea genus exhibit configurational but not geometric isomerism and the stereoisomeric centers (C-22) were identified (Orefice et al., 2015). In contrast, HBIs isolated from $P$. intermedium and $R$. setigera show evidence of homochirality, although they clearly exist as a mixture of geometric isomers (Belt et al., 2001). Also, $\mathrm{C}_{30}$ isoprenoids (triterpenoids) were found in diatoms such as R. setigera (Volkman et al., 1994; Damsté et al., 1999a,b). In addition, one previous study has indicated that the extent of unsaturation in the series of isoprenoids depends on the growth temperature and an increase in growth temperature from 18 to $25^{\circ} \mathrm{C}$ can enhance the degree of unsaturation of $\mathrm{HBI}$ and $Z$ to $E$ isomerization (Rowland et al., 2001). However, the increased salinity has no effects on unsaturation of HBI, but can decrease the unsaturation on $\mathrm{C}_{30}$ compounds (Rowland et al., 2001). Therefore, the diatom $\mathrm{C}_{25}$ and $\mathrm{C}_{30}$ isoprenoids may be used as taxonomic markers and also as an effective tool for tracking carbon flow in shrinking sea ice for understanding the dynamics of climate change and marine ecosystems well (Rowland et al., 2001).

\section{CHEMICAL CHARACTERIZATION}

\section{Extraction and Fractionation of Lipids}

It has been shown that chloroform/methanol extraction could result in higher overall lipid yields than other solvents or solvent pairs by dissolving more polar substances, such as polar lipids (Gunnlaugsdottir and Ackman, 1993). In order to reduce the solvent toxicity from chloroform, alternative solvents or solvent pairs have also been tested, such as methyltert-butyl ether (Matyash et al., 2008), hexane (Danielewicz et al., 2011), and hexane/isopropanol (Hara and Radin, 1978). Hexane extraction results in decreased yields of polar lipids due to its non-polar property. However, the use of hexane would reduce the amount of chlorophyll, which is a major contaminant for lipid extraction (Danielewicz et al., 2011). Different aforementioned solvents have been studied for lipid extraction, and it has been found that chloroform-methanol (1:1) is optimal for a total lipid recovery (Ryckebosch et al., 2012). Therefore, the selection of the extraction solvent is up to the property of target lipid class as well as the safety concern.

Early lipid class composition was analyzed by thin layer chromatography (TLC), mainly by comparing the migration distance of analyte spots with standards (Dunstan et al., 1993). On the advent of solid-phase extraction (SPE) cartridges, lipid classes in diatoms were fractionated using a silica-based SPE method (Yongmanitchai and Ward, 1992). This method is followed by many later studies (Chen et al., 2007; Danielewicz et al., 2011; Ryckebosch et al., 2012). Generally, the cartridge needs to be conditioned with hexane, and neutral lipids, glycolipids, and phospholipids will be eluted stepwise using chloroform, acetone, and methanol according to the polarity of each fraction. The use of hexane instead of chloroform for the conditioning and elution of neutral lipids has also been reported in order to avoid toxicity of chloroform (Danielewicz et al., 2011). It should be noted that phosphatidylcholines, the cholinecontaining phospholipids, might be retained in the SPE column, which could be verified by comparative profiling of each fraction with raw lipid extracts (Danielewicz et al., 2011). Also, each class of lipids could be checked by TLC qualitatively (Fuchs et al., 2011).

\section{Fatty Acid Profiling}

Gas chromatography (GC)-based fatty acid profiling is a routine and well-established method (Seppänen-Laakso et al., 2002). Fatty acids released from lipid saponification, are converted to their corresponding methyl esters and then subjected to GC separation. Fatty acids could be separated by flame ionization using retention times, and identification could be further confirmed by mass spectrometry by comparing the mass to charge ratios $(\mathrm{m} / \mathrm{z})$. To reduce the time-consuming sample preparation steps, a more efficient fatty acid profiling method (Abdulkadir and Tsuchiya, 2008) was developed, where lipid extraction and saponification steps are removed. This approach remains to be assessed in diatom samples. The ratio of polyunsaturated fatty acids to triacylglycerol in lipid samples can also be determined using ${ }^{1} \mathrm{H}$ nuclear magnetic resonance by checking the chemical shift of diagnostic proton (Danielewicz et al., 2011).

\section{Lipidomics for Diatom Lipid Analysis}

Lipidomics is actually the metabolomics of biological lipids. It is advanced by the rapid development of sensitive and high resolution of mass spectrometry as well as lipid identification database, which allows for high-throughput analysis and accurate lipid profiling (Yamada et al., 2013). Processing of lipidomic data can also be achieved with the development of bioinformatics (Niemelä et al., 2009), and data could be visualized in multiple ways, such as principle component analysis plot and heat map, which enables sample classifications and a holistic overview (Bromke et al., 2015). However, the problem is the separation efficiency and ionization of various lipid classes, which could not be fully achieved by ultra-high performance liquid chromatography. For example, isobaric molecules, which have the same $\mathrm{m} / \mathrm{z}$ values and retention times, have the separation issues (Kliman et al., 2011). To this end, ion 
mobility mass spectrometry becomes an emerging technique to characterize lipid isomers with added separation dimension on conformational structure (Kliman et al., 2011; Paglia et al., 2015).

\section{BIOSYNTHETSIS OF FATTY ACIDS AND NEUTRAL LIPIDS IN DIATOMS}

Marine diatoms are excellent producers of highly valuable polyunsaturated fatty acids, such as EPA and DHA. Therefore, it is of particular interest to investigate their biosynthetic pathways, which could be further modified and optimized for industrial production. Figure 2 shows the biosynthesis pathway of long chain fatty acids in the model diatom $P$. tricornutum. AcetylCoA serves as the building block for the elongation of acyl chain by two carbons per elongation step. The elongation of the acyl chain takes place from the malonyl-acyl carrier proteins (ACP) catalyzed by ketoacyl-ACP synthase (KAS). Malonyl-ACPs are formed from acetyl-CoA by carboxylation and transfer of malonyl group to ACP catalyzed by acetylCoA carboxylase (ACCase) and malonyl-CoA: ACP transacylase (MAT), respectively. Fatty acids, including 16:0, 18:0, and $18: 1$, are released from acyl carrier proteins by thioesterases and converted to corresponding acyl-CoAs. EPA and DHA are synthesized from 18:1 after a series of desaturation and elongation reactions mainly following the major route shown in Figure 2.

Interestingly, in diatom $P$. tricornutum, the fatty acid EPA partitions into triacylglycerol, but DHA does not, even though P. tricornutum has a high content of DHA (Tonon et al., 2002). The biosynthesis of TAG is also affected by other catabolic metabolites, such as branched-chain amino acid degradation pathway (Ge et al., 2014). Thus, the accumulation of TAG should be understood at a system level, rather than only limited to the fatty acid synthesis pathway.

In general, for the application of diatom lipids in food or pharmaceuticals, the incorporation of long chain PUFA into TAG is preferred, so that PUFA-containing lipids could be concentrated in oil bodies (Tonon et al., 2002), while the biofuel industry would be in favor of the production of saturated short to medium length chain fatty acid-containing TAGs, which have low cloud points and resistance to oxidation (Stournas et al., 1995). So engineering strategies may be optimized in different scenarios.

\section{Mutagenesis}

Mutagens were usually classified as physical mutagens and chemical mutagens (Sparrow et al., 1974). Physical mutagens involve different kinds of irradiation such as UV, $\gamma$, and heavy ion beams. Due to easy implementation, UV has been known to be the most widely applied physical mutagen (Hlavova et al., 2015; Yi et al., 2015). UV light has strong genotoxic effect which induces DNA damage such as the formation of cyclobutane pyrimidine dimers (CPDs) and pyrimidine pyrimidone photoproducts (64 PPs) (Ikehata and Ono, 2011). It was reported that EPA production in $P$. tricornutum was increased by $33 \%$ through UV mutagenesis (Alonso et al., 1996). Chemical mutagens that were most frequently used in microalgae were alkylating agents such as methylnitronitrosoguanidine (MNNG) and ethyl methanesulfonate (EMS) (Kamath et al., 2008). To date, only EMS has been reportedly applied on diatoms to achieve higher lipid production. Novel strains created by EMS exhibited 2-2.5 fold enhancement in total lipid content in P. tricornutum than wild type without compromising growth and biomass production (Kaur, 2014). However, certain positive mutants have lower expression of phospholipids and some mutants accumulated long

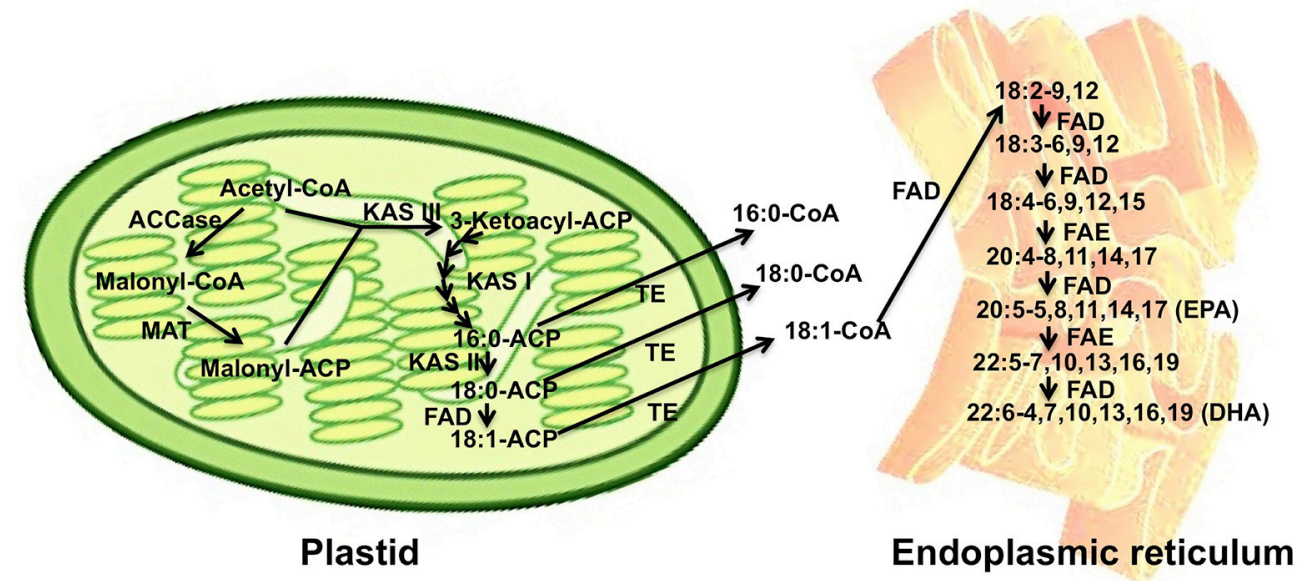

FIGURE 2 | A scheme of long chain fatty acid biosynthesis pathway in the model species $P$. tricornutum and compartmentation of biosynthesis processes in plastid (left) and endoplasmic reticulum (right). Major biosynthetic routes for EPA and DHA biosynthesis are illustrated as examples, and for other routes one can refer to the previous studies (Arao and Yamada, 1994; Hamilton et al., 2014). Abbreviations: ACCase, acetyl-CoA Carboxylase; MAT, malonyl-CoA acyl carrier protein transacylase; KAS I, II, and III, isoform I, II, and III of ketoacyl-acyl carrier protein synthase; FAD, fatty acid desaturase; TE, thioesterase; FAE, fatty acid elongase. These enzymes in each group of TEs, FADs, or FAEs in the Figure 2 are not identical but substrate-specific. 
chain fatty acids such as nervonic acid (C24:1) and erucic (C22:1) acid. All selected positive mutants exhibited higher activity of fatty acid synthase ketoacyl-acyl carrier protein synthase I (FABB) and ketoacyl-acyl carrier protein synthase II (FABFs) (Kaur, 2014).

\section{Environmental Stimulants}

Environmental stressors play a crucial role in diatom biomass and lipid production. Under favorable growth environment, diatoms grow rapidly with relatively low lipid contents. Environmental stresses usually reduce diatom growth rate, but result in higher lipid accumulation. Nonetheless, the mechanism has not been well understood. Nitrogen is vital to diatom's proper physiological functions, and it is a key component in metabolism of amino acids, nucleic acids, and photosynthetic pigments and its uptake is at the highest level among all nutrients (Yang et al., 2013). Accordingly, pigments reduction has been observed in Antarctic sea ice diatoms under nitrogen deficiency (Eppley, 1972). Nitrogen deprivation is a common method to enhance lipid contents in diatoms. Nitrogen deprived P. tricornutum cells accumulated higher lipid level regardless of the stoppage of their cell divisions and slight increase of cell density. In order to achieve higher lipid productivity, diatoms were first cultured under optimal growth conditions to achieve high biomass and then transferred to nitrogen starvation condition to get high lipid content for massive production (Yang et al., 2013). Phosphorus is another vital component in phospholipids and nucleic acids and it has an essential role in physiological processes such as respiration and photosynthesis (Wurch et al., 2011). Changes of the growth rate, cell size and pigment composition and lipid content in microalgae have been studied under phosphorus deprivation (Wurch et al., 2011). P. tricorntum had a 2fold increase in fatty acid content but reduced in a half in biomass production under phosphorus starvation environment (Wurch et al., 2011). In most diatom species, silicon is one key component of cell wall structure and therefore a limiting micro-nutrient for diatom biomass production (Roessler, 1988). The acetyl-CoA carboxylase activity was enhanced by 2 -fold and 4 -fold respectively after 4 and $15 \mathrm{~h}$ growth without silicate in Cyclotella cryptica (Roessler, 1988). Light irradiation is also well known to modulate lipid content in algae and under photooxidative stress microalgae are capable to produce extra TAGs (Khotimchenko and Yakovleva, 2005; Hu et al., 2008). Under UV-A and UV-B radiation, lipid accumulation could be induced in a very short time $(\leq 1 \mathrm{~h})$ in Nitzschia palea (Arts et al., 2000).

\section{Genetic Modifications}

Various genetic modification approaches have been applied on diatoms (Armbrust et al., 2004; Hu et al., 2008; Niu et al., 2013). P. tricornutum over-expressing heterologous thioesterase increased $72 \%$ of total fatty acid content (Gong et al., 2011). Two heterologous thioesterase genes were inserted into $P$. tricornutum and ratios of C12 and C14 fatty acids to total fatty acids increased (Radakovits et al., 2011). T. pseudonana exhibited increased lipid yields from the knockdown of a multi-functional lipase without affecting diatom growth (Trentacoste et al., 2013). Knocking down the genes encoding the decarboxylation enzyme phosphoenolpyruvate carboxykinase (PEPCK) and UDP-glucose pyrophosphorylase (UGPase) resulted in down-regulated decarboxylation and up-regulated lipid synthesis in P. tricornutum (Yang et al., 2016). Meganucleases (MNs) and transcription activator-like effector nuleases (TALEN) were utilized to induce targeted mutagenesis (TM) of lipid metabolic genes and generated one strain with 45-fold enhancement in triacylglycerol accumulation in P. tricornutum (Daboussi et al., 2014). Recently, Clustered Regularly Interspaced Short Palindromic Repeats and their associated proteins (CRISPR/Cas9) system has been successfully applied in P. tricornutum and T. pseudonana to create stable mutants (Hopes et al., 2016; Nymark et al., 2016), but to our knowledge there was no reports on editing lipid metabolic genes using CRISPR/Cas9 system yet.

\section{CONCLUSIONS AND PERSPECTIVES}

Diatoms are a promising oil feedstock and energy source as they accumulate a large amount of lipids consisting of TAGs and diverse fatty acids. Many valuable lipids and lipid derivatives such as essential fatty acids, steroids, and oxylipins can be produced in diatoms in natural growth environment. Obviously, algal oils have advantages over fish oils for being a vegan or vegetarian diet because they don't contain any animal products. In addition, the environmentally friendly property of algae makes algal oils a strong substitute for fish oils in response to decreasing fish stocks. Meanwhile, marine algae are actually the source of essential fatty acids for fish oil production, as they comprise the major diets of fish, which suggests that algal oils contain the omega-3 fatty acids that body can utilize and benefit from. As a major group of algae, diatom-derived algal oils may be preferred and gain great attention in global market for their potentials in sustainable production in comparison with fish oils.

Further studies may emphasize on the lipid productivity improvement in diatoms. Advanced metabolic engineering tools such as CRISPR/Cas9 system may be applied to create strains that accumulate specific fatty acids such as EPA and DHA. With the understanding of biosynthetic pathways of lipids in model and other diatom species, synthetic biology tools could be designed and applied for high-throughput strain development. In addition, research efforts should be made to achieve simultaneous production of a group of valuable and interrelated compounds as diatoms can generate a variety of valuable products.

\section{AUTHOR CONTRIBUTIONS}

$\mathrm{ZY}, \mathrm{MX}$, and XD were responsible for the literature review, analysis and interpretation, as well as drafting the manuscript. SB and WF were responsible for conducting the work. WF conceived this study and also helped to draft the manuscript. All authors contributed to the critical revision of the article and the final approval of the manuscript. 


\section{ACKNOWLEDGMENTS}

This work was supported by Iceland National Research Funds (Rannis/Technology Development Fund) with

\section{REFERENCES}

Abdulkadir, S., and Tsuchiya, M. (2008). One-step method for quantitative and qualitative analysis of fatty acids in marine animal samples. J. Exp. Mar. Biol. Ecol. 354, 1-8. doi: 10.1016/j.jembe.2007.08.024

Adolph, S., Poulet, S. A., and Pohnert, G. (2003). Synthesis and biological activity of $\alpha, \beta, \gamma, \delta$-unsaturated aldehydes from diatoms. Tetrahedron 59, 3003-3008. doi: 10.1016/S0040-4020(03)00382-X

Alonso, D. L., Delcastillo, C. I. S., Grima, E. M., and Cohen, Z. (1996). First insights into improvement of eicosapentaenoic acid content in Phaeodactylum tricornutum (Bacillariophyceae) by induced mutagenesis. J. Phycol. 32, 339-345. doi: 10.1111/j.0022-3646.1996.00339.x

Anderson, R., Kates, M., and Volcani, B. (1978). Identification of the sulfolipids in the non-photosynthetic diatom Nitzschia alba. Biochim. Biophys. Acta 528, 89-106. doi: 10.1016/0005-2760(78)90055-3

Appeltans, W., Ahyong, S. T., Anderson, G., Angel, M. V., Artois, T., Bailly, N., et al. (2012). The magnitude of global marine species diversity. Curr. Biol. 22, 2189-2202. doi: 10.1016/j.cub.2012.09.036

Arao, T., and Yamada, M. (1994). Biosynthesis of polyunsaturated fatty acids in the marine diatom, Phaeodactylum tricornutum. Phytochemistry 35, 1177-1181. doi: 10.1016/S0031-9422(00)94817-9

Armbrust, E. V., Berges, J. A., Bowler, C., Green, B. R., Martinez, D., Putnam, N. H., et al. (2004). The genome of the diatom Thalassiosira pseudonana: ecology, evolution, and metabolism. Science 306, 79-86. doi: 10.1126/science.1101156

Arts, M. T., Rai, H., and Tumber, V. P. (2000). Effects of artificial UV-A and UVB radiation on carbon allocation in Synechococcus elongatus (cyanobacterium) and Nitzschia palea (diatom). Int. Vereinigung fur Theor. Angewandte Limnol. Verhandlungen 27, 1-8.

Bates, S., and Trainer, V. (2006). The Ecology of Harmful Diatoms Ecology of Harmful Algae. Heidelberg: Springer.

Belt, S. T., Allard, W. G., Johns, L., König, W. A., Massé, G., Robert, J. M., et al. (2001). Variable stereochemistry in highly branched isoprenoids from diatoms. Chirality 13, 415-419. doi: 10.1002/chir.1053

Bromke, M. A., Sabir, J. S., Alfassi, F. A., Hajarah, N. H., Kabli, S. A., AlMalki, A. L., et al. (2015). Metabolomic profiling of 13 diatom cultures and their adaptation to nitrate-limited growth conditions. PLoS ONE 10:e0138965. doi: 10.1371/journal.pone. 0138965

Caldwell, G. S. (2009). The influence of bioactive oxylipins from marine diatoms on invertebrate reproduction and development. Mar. Drugs 7, 367-400. doi: $10.3390 / \mathrm{md} 7030367$

Chen, G.-Q., Jiang, Y., and Chen, F. (2007). Fatty acid and lipid class composition of the eicosapentaenoic acid-producing microalga, Nitzschia laevis. Food Chem. 104, 1580-1585. doi: 10.1016/j.foodchem.2007.03.008

Cutignano, A., Lamari, N., Manzo, E., Cimino, G., and Fontana, A. (2011). Lipoxygenase products in marine diatoms: a concise analytical method to explore the functional potential of oxylipins1. J. Phycol. 47, 233-243. doi: 10.1111/j.1529-8817.2011.00972.x

Daboussi, F., Leduc, S., Marechal, A., Dubois, G., Guyot, V., PerezMichaut, C., et al. (2014). Genome engineering empowers the diatom Phaeodactylum tricornutum for biotechnology. Nat. Commun. 5:3831. doi: 10.1038/ncomms4831

da Costa, E., Silva, J., Mendonça, S. H., Abreu, M. H., and Domingues, M. R. (2016). Lipidomic approaches towards deciphering glycolipids from microalgae as a reservoir of bioactive lipids. Mar. Drugs 14:101. doi: 10.3390/md14050101

Damsté, J. S. S., Rijpstra, W. I. C., Schouten, S., Peletier, H., Van Der Maarel, M. J., and Gieskes, W. W. (1999a). AC 25 highly branched isoprenoid alkene and C 25 and C $27 \mathrm{n}$-polyenes in the marine diatom Rhizosolenia setigera. Org. Geochem. 30, 95-100. doi: 10.1016/S0146-6380(98)00141-7

Damsté, J. S. S., Schouten, S., Rijpstra, W. I. C., Hopmans, E. C., Peletier, H., Gieskes, W. W., et al. (1999b). Structural identification of the C 25 highly a grant number 163922-0611 and additional support for WF was provided by New York University Abu Dhabi (NYUAD) Faculty Research Funds AD060.

branched isoprenoid pentaene in the marine diatom Rhizosolenia setigera. Org. Geochem. 30, 1581-1583. doi: 10.1016/S0146-6380(99)00140-0

Damsté, J. S. S., Schouten, S., Rijpstra, W. I. C., Hopmans, E. C., Peletier, H., Gieskes, W. W., et al. (2000). Novel polyunsaturated n-alkenes in the marine diatom Rhizosolenia setigera. Eur. J. Biochem. 267, 5727-5732. doi: 10.1046/j.1432-1327.2000.01636.x

Danielewicz, M. A., Anderson, L. A., and Franz, A. K. (2011). Triacylglycerol profiling of marine microalgae by mass spectrometry. J. Lipid Res. 52, 2101-2108. doi: 10.1194/jlr.D018408

Desbois, A. P., Lebl, T., Yan, L., and Smith, V. J. (2008). Isolation and structural characterisation of two antibacterial free fatty acids from the marine diatom, Phaeodactylum tricornutum. Appl. Microbiol. Biotechnol. 81, 755-764. doi: 10.1007/s00253-008-1714-9

D’ippolito, G., Cutignano, A., Briante, R., Febbraio, F., Cimino, G., and Fontana, A. (2005). New C 16 fatty-acid-based oxylipin pathway in the marine diatom Thalassiosira rotula. Org. Biomol. Chem. 3, 4065-4070. doi: 10.1039/b510640k

d'ippolito, G., Sardo, A., Paris, D., Vella, F. M., Adelfi, M. G., Botte, P., et al. (2015). Potential of lipid metabolism in marine diatoms for biofuel production. Biotechnol. Biofuels 8, 28. doi: 10.1186/s13068-015-0212-4

Dunstan, G. A., Volkman, J. K., Barrett, S. M., Leroi, J.-M., and Jeffrey, S. (1993). Essential polyunsaturated fatty acids from 14 species of diatom (Bacillariophyceae). Phytochemistry 35, 155-161. doi: 10.1016/S00319422(00)90525-9

Eppley, R. W. (1972). Temperature and phytoplankton growth in the sea. Fish. Bull 70, 1063-1085.

Frenkel, J., Wess, C., Vyverman, W., and Pohnert, G. (2014). Chiral separation of a diketopiperazine pheromone from marine diatoms using supercritical fluid chromatography. J. Chromatogr. B 951, 58-61. doi: 10.1016/j.jchromb.2013.12.040

Fu, W. Q., Wichuk, K., and Brynjolfsson, S. (2015). Developing diatoms for valueadded products: challenges and opportunities. N. Biotechnol. 32, 547-551. doi: 10.1016/j.nbt.2015.03.016

Fuchs, B., Süß, R., Teuber, K., Eibisch, M., and Schiller, J. (2011). Lipid analysis by thin-layer chromatography-a review of the current state. J. Chromatogr. A 1218, 2754-2774. doi: 10.1016/j.chroma.2010.11.066

Ge, F., Huang, W., Chen, Z., Zhang, C., Xiong, Q., Bowler, C., et al. (2014). Methylcrotonyl-CoA carboxylase regulates triacylglycerol accumulation in the model diatom Phaeodactylum tricornutum. Plant Cell 26, 1681-1697. doi: 10.1105/tpc.114.124982

Girona, J., La Ville, A. E., Heras, M., Olivé, S., and Masana, L. (1997). Oxidized lipoproteins including HDL and their lipid peroxidation products inhibit TNF$\alpha$ secretion by THP-1 human macrophages. Free Radic. Biol. Med. 23, 658-667. doi: 10.1016/S0891-5849(97)00061-0

Gong, Y., Guo, X., Wan, X., Liang, Z., and Jiang, M. (2011). Characterization of a novel thioesterase (PtTE) from Phaeodactylum tricornutum. J. Basic Microbiol. 51, 666-672. doi: 10.1002/jobm.201000520

Grossi, V., Beker, B., Geenevasen, J. A., Schouten, S., Raphel, D., Fontaine, M.-F., et al. (2004). C 25 highly branched isoprenoid alkenes from the marine benthic diatom Pleurosigma strigosum. Phytochemistry 65, 3049-3055. doi: 10.1016/j.phytochem.2004.09.002

Guiry, M. D. (2012). How many species of algae are there? J. Phycol. 48, 1057-1063. doi: $10.1111 /$ j.1529-8817.2012.01222.x

Gunnlaugsdottir, H., and Ackman, R. G. (1993). Three extraction methods for determination of lipids in fish meal: evaluation of a hexane/isopropanol method as an alternative to chloroform-based methods. J. Sci. Food Agric. 61, 235-240. doi: $10.1002 /$ jsfa. 2740610216

Hallahan, B., and Garland, M. R. (2005). Essential fatty acids and mental health. Br. J. Psychiatry 186, 275-277. doi: 10.1192/bjp.186.4.275

Hamilton, M. L., Haslam, R. P., Napier, J. A., and Sayanova, O. (2014). Metabolic engineering of Phaeodactylum tricornutum for the enhanced accumulation 
of omega-3 long chain polyunsaturated fatty acids. Metab. Eng. 22, 3-9. doi: 10.1016/j.ymben.2013.12.003

Hamilton, M. L., Warwick, J., Terry, A., Allen, M. J., Napier, J. A., and Sayanova, O. (2015). Towards the industrial production of Omega-3 long chain polyunsaturated fatty acids from a genetically modified diatom Phaeodactylum tricornutum. PLoS ONE 10:e0144054. doi: 10.1371/journal.pone.0144054

Hara, A., and Radin, N. S. (1978). Lipid extraction of tissues with a low-toxicity solvent. Anal. Biochem. 90, 420-426. doi: 10.1016/0003-2697(78)90046-5

Hildebrand, M., Davis, A. K., Smith, S. R., Traller, J. C., and Abbriano, R. (2012). The place of diatoms in the biofuels industry. Biofuels 3, 221-240. doi: 10.4155/bfs.11.157

Hlavova, M., Turoczy, Z., and Bisova, K. (2015). Improving microalgae for biotechnology - From genetics to synthetic biology. Biotechnol. Adv. 33, 1194-1203. doi: 10.1016/j.biotechadv.2015.01.009

Hopes, A., Nekrasov, V., Kamoun, S., and Mock, T. (2016). Editing of the urease gene by CRISPR-Cas in the diatom Thalassiosira pseudonana. bioRxiv 062026. doi: 10.1186/s13007-016-0148-0

Hu, Q., Sommerfeld, M., Jarvis, E., Ghirardi, M., Posewitz, M., Seibert, M., et al. (2008). Microalgal triacylglycerols as feedstocks for biofuel production: perspectives and advances. Plant J. 54, 621-639. doi: 10.1111/j.1365313X.2008.03492.x

Ikehata, H., and Ono, T. (2011). The mechanisms of UV mutagenesis. J. Radiat. Res. 52, 115-125. doi: 10.1269/jrr.10175

Jiang, X., Han, Q., Gao, X., and Gao, G. (2016). Conditions optimising on the yield of biomass, total lipid, and valuable fatty acids in two strains of Skeletonema menzelii. Food Chem. 194, 723-732. doi: 10.1016/j.foodchem.2015.08.073

Jump, D. B., Depner, C. M., and Tripathy, S. (2012). Omega-3 fatty acid supplementation and cardiovascular disease Thematic Review Series: new lipid and lipoprotein targets for the treatment of cardiometabolic diseases. J. Lipid Res. 53, 2525-2545. doi: 10.1194/jlr.R027904

Kabara, J. J., Swieczkowski, D. M., Conley, A. J., and Truant, J. P. (1972). Fatty acids and derivatives as antimicrobial agents. Antimicrob. Agents Chemother. 2, 23-28. doi: 10.1128/AAC.2.1.23

Kamath, B. S., Vidhyavathi, R., Sarada, R., and Ravishankar, G. A. (2008). Enhancement of carotenoids by mutation and stress induced carotenogenic genes in Haematococcus pluvialis mutants. Bioresour. Technol. 99, 8667-8673. doi: 10.1016/j.biortech.2008.04.013

Kaur, S. (2014). Genetic and Biotechnological Development of the pennate marine diatom Phaeodactylum tricornutum for high-value bioproducts and carbon bio-mitigation. Doctoral thesis. Galway: National University of Ireland.

Khotimchenko, S. V., and Yakovleva, I. M. (2005). Lipid composition of the red alga Tichocarpus crinitus exposed to different levels of photon irradiance. Phytochemistry 66, 73-79. doi: 10.1016/j.phytochem.2004.10.024

Kliman, M., May, J. C., and McLean, J. A. (2011). Lipid analysis and lipidomics by structurally selective ion mobility-mass spectrometry. Biochim. Biophys. Acta 1811, 935-945. doi: 10.1016/j.bbalip.2011.05.016

Kröger, N., Deutzmann, R., and Sumper, M. (1999). Polycationic peptides from diatom biosilica that direct silica nanosphere formation. Science 286, 1129-1132. doi: 10.1126/science.286.5442.1129

Lafourcade, M., Larrieu, T., Mato, S., Duffaud, A., Sepers, M., Matias, I., et al. (2011). Nutritional omega-3 deficiency abolishes endocannabinoid-mediated neuronal functions. Nat. Neurosci. 14, 345-350. doi: 10.1038/nn.2736

Lauritano, C., Romano, G., Roncalli, V., Amoresano, A., Fontanarosa, C., Bastianini, M., et al. (2016). New oxylipins produced at the end of a diatom bloom and their effects on copepod reproductive success and gene expression levels. Harmful Algae 55, 221-229. doi: 10.1016/j.hal.2016.03.015

Levitan, O., Dinamarca, J., Hochman, G., and Falkowski, P. G. (2014). Diatoms: a fossil fuel of the future. Trends Biotechnol. 32, 117-124. doi: 10.1016/j.tibtech.2014.01.004

Li, S., Xu, J., Chen, J., Chen, J., Zhou, C., and Yan, X. (2014). Characterization of the triacylglycerol profile in marine diatoms by ultra performance liquid chromatography coupled with electrospray ionization-quadrupole time-of-flight mass spectrometry. J. Appl. Phycol. 26, 1389-1398. doi: 10.1007/s10811-013-0159-4

Mangas-Sanchez, J., and Adlercreutz, P. (2015). Highly efficient enzymatic biodiesel production promoted by particle-induced emulsification. Biotechnol. Biofuels 8:58. doi: 10.1186/s13068-015-0247-6
Mann, D. G., and Droop, S., J., M. (1996). Biodiversity, biogeography and conservation of diatoms. Hydrobiologia 336, 19-32. doi: 10.1007/BF00010816

Mansour, M. P., Frampton, D. M., Nichols, P. D., Volkman, J. K., and Blackburn, S. I. (2005). Lipid and fatty acid yield of nine stationary-phase microalgae: applications and unusual C24-C28 polyunsaturated fatty acids. J. Appl. Phycol. 17, 287-300. doi: 10.1007/s10811-005-6625-x

Matyash, V., Liebisch, G., Kurzchalia, T. V., Shevchenko, A., and Schwudke, D. (2008). Lipid extraction by methyl-tert-butyl ether for high-throughput lipidomics. J. Lipid Res. 49, 1137-1146. doi: 10.1194/jlr.D700041-JLR200

Michalak, I., and Chojnacka, K. (2015). Algae as production systems of bioactive compounds. Eng. Life Sci. 15, 160-176. doi: 10.1002/elsc.201400191

Nakamura, M. T., and Nara, T. Y. (2004). Structure, function, and dietary regulation of $\Delta 6, \Delta 5$, and $\Delta 9$ desaturases. Annu. Rev. Nutr. 24, 345-376. doi: 10.1146/annurev.nutr.24.121803.063211

Nanjappa, D., d'ippolito, G., Gallo, C., Zingone, A., and Fontana, A. (2014). Oxylipin diversity in the diatom family Leptocylindraceae reveals DHA derivatives in marine diatoms. Mar. Drugs 12, 368-384. doi: $10.3390 / \mathrm{md} 12010368$

Nappez, C., Battu, S., and Beneytout, J. (1996). trans, trans-2, 4-Decadienal: cytotoxicity and effect on glutathione level in human erythroleukemia (HEL) cells. Cancer Lett. 99, 115-119. doi: 10.1016/0304-3835(95)04045-5

Niemelä, P. S., Castillo, S., Sysi-Aho, M., and Orešič, M. (2009). Bioinformatics and computational methods for lipidomics. J. Chromatogr. B 877, 2855-2862. doi: 10.1016/j.jchromb.2009.01.025

Niu, Y. F., Zhang, M. H., Li, D. W., Yang, W. D., Liu, J. S., Bai, W. B., et al. (2013). Improvement of neutral lipid and polyunsaturated fatty acid biosynthesis by overexpressing a Type 2 diacylglycerol acyltransferase in marine diatom Phaeodactylum tricornutum. Mar. Drugs 11, 4558-4569. doi: $10.3390 / \mathrm{md} 11114558$

Nymark, M., Sharma, A. K., Sparstad, T., Bones, A. M., and Winge, P. (2016). A CRISPR/Cas9 system adapted for gene editing in marine algae. Sci. Rep. 6:24951. doi: 10.1038/srep24951

Opute, F. I. (1974). Lipid and fatty-acid composition of diatoms. J. Exp. Bot. 25, 823-835. doi: $10.1093 / \mathrm{jxb} / 25.4 .823$

Orefice, I., Gerecht, A., D’ippolito, G., Fontana, A., Ianora, A., and Romano, G. (2015). Determination of lipid hydroperoxides in marine diatoms by the FOX2 Assay. Mar. Drugs 13, 5767-5783. doi: 10.3390/md13095767

Paglia, G., Kliman, M., Claude, E., Geromanos, S., and Astarita, G. (2015). Applications of ion-mobility mass spectrometry for lipid analysis. Anal. Bioanal. Chem. 407, 4995-5007. doi: 10.1007/s00216-015-8664-8

Paul, V. J., and Fenical, W. (1986). Chemical defense in tropical green algae, order Caulerpales. Mar. Ecol. Prog. Ser. 34, 157-169. doi: 10.3354/meps034157

Plouguerné, E., Da Gama, B. A., Pereira, R. C., and Barreto-Bergter, E. (2014). Glycolipids from seaweeds and their potential biotechnological applications. Front. Cell. Infect. Microbiol. 4:174. doi: 10.3389/fcimb.2014.00174

Radakovits, R., Eduafo, P. M., and Posewitz, M. C. (2011). Genetic engineering of fatty acid chain length in Phaeodactylum tricornutum. Metab. Eng. 13, 89-95. doi: 10.1016/j.ymben.2010.10.003

Rampen, S. W., Abbas, B. A., Schouten, S., and Damsté, J. S. S. (2010). A comprehensive study of sterols in marine diatoms (Bacillariophyta) implications for their use as tracers for diatom productivity. Limnol. Oceanogr. 55:91. doi: 10.4319/lo.2010.55.1.0091

Rampen, S. W., Schouten, S., Hopmans, E. C., Abbas, B., Noordeloos, A. A., Geenevasen, J. A., et al. (2009a). Occurrence and biomarker potential of 23-methyl steroids in diatoms and sediments. Org. Geochem. 40, 219-228. doi: 10.1016/j.orggeochem.2008.10.006

Rampen, S. W., Schouten, S., Hopmans, E. C., Abbas, B., Noordeloos, A. A., Van Bleijswijk, J. D., et al. (2009b). Diatoms as a source for 4-desmethyl-23, 24dimethyl steroids in sediments and petroleum. Geochim. Cosmochim. Acta 73, 377-387. doi: 10.1016/j.gca.2008.10.024

Roessler, P. G. (1988). Effects of silicon deficiency on lipid-composition and metabolism in the diatom cyclotella-cryptica. J. Phycol. 24, 394-400. doi: 10.1111/j.1529-8817.1988.tb00189.x

Rowland, S., Allard, W., Belt, S., Massé, G., Robert, J.-M., Blackburn, S., et al. (2001). Factors influencing the distributions of polyunsaturated terpenoids in the diatom, Rhizosolenia setigera. Phytochemistry 58, 717-728. doi: 10.1016/S0031-9422(01)00318-1 
Ryckebosch, E., Muylaert, K., and Foubert, I. (2012). Optimization of an analytical procedure for extraction of lipids from microalgae. J. Am. Oil Chem. Soc. 89, 189-198. doi: 10.1007/s11746-011-1903-Z

Sansone, C., Braca, A., Ercolesi, E., Romano, G., Palumbo, A., Casotti, R., et al. (2014). Diatom-derived polyunsaturated aldehydes activate cell death in human cancer cell lines but not normal cells. PLOS ONE 9:e101220. doi: 10.1371/journal.pone.0101220

Sapieha, P., Stahl, A., Chen, J., Seaward, M. R., Willett, K. L., Krah, N. M., et al. (2011). 5-Lipoxygenase metabolite 4-HDHA is a mediator of the antiangiogenic effect of $\omega-3$ polyunsaturated fatty acids. Sci. Trans. Med. 3, 69ra12-69ra12. doi: 10.1126/scitranslmed.3001571

Seppänen-Laakso, T., Laakso, I., and Hiltunen, R. (2002). Analysis of fatty acids by gas chromatography, and its relevance to research on health and nutrition. Anal. Chim. Acta 465, 39-62. doi: 10.1016/S0003-2670(02)00397-5

Sieg, R. D., Poulson-Ellestad, K. L., and Kubanek, J. (2011). Chemical ecology of the marine plankton. Nat. Prod. Rep. 28, 388-399. doi: 10.1039/C0NP00051E

Sparrow, A. H., Schairer, L. A., and Villalobos-Pietrini, R. (1974). Comparison of somatic mutation rates induced in Tradescantia by chemical and physical mutagens. Mutat. Res. 26, 265-276. doi: 10.1016/S0027-5107(74)80024-2

Stonik, V., and Stonik, I. (2015). Low-molecular-weight metabolites from diatoms: structures, biological roles and biosynthesis. Mar Drugs 13, 3672-3709. doi: $10.3390 / \mathrm{md} 13063672$

Stournas, S., Lois, E., and Serdari, A. (1995). Effects of fatty acid derivatives on the ignition quality and cold flow of diesel fuel. J. Am. Oil Chem. Soc. 72, 433-437. doi: 10.1007/BF02636084

Thompson, G. A. (1996). Lipids and membrane function in green algae. Biochim. Biophys. Acta 1302, 17-45. doi: 10.1016/0005-2760(96)00045-8

Tonon, T., Harvey, D., Larson, T. R., and Graham, I. A. (2002). Long chain polyunsaturated fatty acid production and partitioning to triacylglycerols in four microalgae. Phytochemistry 61, 15-24. doi: 10.1016/S00319422(02)00201-7

Trentacoste, E. M., Shrestha, R. P., Smith, S. R., Gle, C., Hartmann, A. C., Hildebrand, M., et al. (2013). Metabolic engineering of lipid catabolism increases microalgal lipid accumulation without compromising growth. Proc. Natl. Acad. Sci. U.S.A. 110, 19748-19753. doi: 10.1073/pnas.1309299110

Trumbo, P., Schlicker, S., Yates, A. A., and Poos, M. (2002). Dietary reference intakes for energy, carbohydrate, fiber, fat, fatty acids, cholesterol, protein and amino acids. J. Am. Diet. Assoc. 102, 1621-1630. doi: 10.1016/S00028223(02)90346-9

Valenzuela, R. W., Sanhueza, J., and Valenzuela, A. (2012). Docosahexaenoic acid (DHA), an important fatty acid in aging and the protection of neurodegenerative diseases. J. Nutr. Ther. 1, 63-72. doi: 10.6000/19295634.2012.01.01.6

Viegelmann, C., Parker, J., Ooi, T., Clements, C., Abbott, G., Young, L., et al. (2014). Isolation and identification of antitrypanosomal and antimycobacterial active steroids from the sponge haliclona simulans. Mar. Drugs 12, 2937-2952. doi: $10.3390 / \mathrm{md} 12052937$

Vilchez, C., Forjan, E., Cuaresma, M., Bedmar, F., Garbayo, I., and Vega, J. M. (2011). Marine carotenoids: biological functions and commercial applications. Mar. Drugs 9, 319-333. doi: 10.3390/md9030319

Vinayak, V., Manoylov, K. M., Gateau, H., Blanckaert, V., Herault, J., Pencreac'h, G., et al. (2015). Diatom milking: a review and new approaches. Mar. Drugs 13, 2629-2665. doi: 10.3390/md13052629

Volkman, J. K., Barrett, S. M., Blackburn, S. I., Mansour, M. P., Sikes, E. L., and Gelin, F. (1998). Microalgal biomarkers: a review of recent research developments. Org. Geochem. 29, 1163-1179. doi: 10.1016/S01466380(98)00062-X

Volkman, J. K., Barrett, S. M., and Dunstan, G. A. (1994). C25 and C30 highly branched isoprenoid alkenes in laboratory cultures of two marine diatoms. Org. Geochem. 21, 407-414. doi: 10.1016/0146-6380(94)90202-X

Wang, R., and Shimizu, Y. (1990). Bacillariolides I and II, a new type of cyclopentane eicosanoids from the diatom Nitzschia pungens. J. Chem. Soc. Chem. Commun. 5, 413-414. doi: 10.1039/c39900000413

Wichard, T., and Pohnert, G. (2006). Formation of halogenated medium chain hydrocarbons by a lipoxygenase/hydroperoxide halolyase-mediated transformation in planktonic microalgae. J. Am. Chem. Soc. 128, 7114-7115. doi: $10.1021 / \mathrm{ja} 057942 \mathrm{u}$

Wichard, T., Poulet, S. A., Halsband-Lenk, C., Albaina, A., Harris, R., Liu, D., et al. (2005). Survey of the chemical defence potential of diatoms: screening of fifty species for $\alpha, \beta, \gamma, \delta$-unsaturated aldehydes. J. Chem. Ecol. 31, 949-958. doi: 10.1007/s10886-005-3615-z

Wurch, L. L., Bertrand, E. M., Saito, M. A., Van Mooy, B. A. S., and Dyhrman, S. T. (2011). Proteome changes driven by phosphorus deficiency and recovery in the brown tide-forming alga aureococcus anophagefferens. PLoS ONE 6:e28949. doi: 10.1371/journal.pone.0028949

Yamada, T., Uchikata, T., Sakamoto, S., Yokoi, Y., Fukusaki, E., and Bamba, T. (2013). Development of a lipid profiling system using reverse-phase liquid chromatography coupled to high-resolution mass spectrometry with rapid polarity switching and an automated lipid identification software. $J$. Chromatogr. A. 1292, 211-218. doi: 10.1016/j.chroma.2013.01.078

Yang, J., Pan, Y. F., Bowler, C., Zhang, L. X., and Hu, H. H. (2016). Knockdown of phosphoenolpyruvate carboxykinase increases carbon flux to lipid synthesis in Phaeodactylum tricornutum. Algal Res. Biomass Biofuels Bioproducts 15, 50-58. doi: 10.1016/j.algal.2016.02.004

Yang, Z.-K., Niu, Y.-F., Ma, Y.-H., Xue, J., Zhang, M.-H., Yang, W.-D., et al. (2013). Molecular and cellular mechanisms of neutral lipid accumulation in diatom following nitrogen deprivation. Biotechnol. Biofuels 6, 1-14. doi: 10.1186/1754-6834-6-67

Yi, Z., Xu, M., Magnusdottir, M., Zhang, Y., Brynjolfsson, S., and Fu, W. (2015). Photo-oxidative stress-driven mutagenesis and adaptive evolution on the marine diatom Phaeodactylum tricornutum for enhanced carotenoid accumulation. Mar. Drugs 13, 6138-6151. doi: 10.3390/md131 06138

Yongmanitchai, W., and Ward, O. (1992). Separation of lipid classes from Phaeodactylum tricornutum using silica cartridges. Phytochemistry 31, 3405-3408. doi: 10.1016/0031-9422(92)83694-T

Zheng, N., and Shimizu, Y. (1997). The isolation and structure of bacillariolide III, an extracellularmetabolite of the diatom, Pseudo-nitzschia multiseries. Chem. Commun. 4, 399-400. doi: 10.1039/a608369b

Conflict of Interest Statement: The authors declare that the research was conducted in the absence of any commercial or financial relationships that could be construed as a potential conflict of interest.

Copyright (c) 2017 Yi, Xu, Di, Brynjolfsson and Fu. This is an open-access article distributed under the terms of the Creative Commons Attribution License (CC BY). The use, distribution or reproduction in other forums is permitted, provided the original author(s) or licensor are credited and that the original publication in this journal is cited, in accordance with accepted academic practice. No use, distribution or reproduction is permitted which does not comply with these terms. 